\title{
Characteristic Cochlear Hypoplasia in Patients with Walker- Warburg Syndrome: A Radiologic Study of the Inner Ear in $\alpha$-Dystroglycan-Related Muscular Disorders
}

(D) G. Talenti, (DC. Robson, (D) M.S. Severino, (DC.A. Alves, DD. Chitayat, (DH. Dahmoush, (D). Smith, (D). Muntoni, DS.I. Blaser, and (DF. D'Arco

\begin{abstract}
BACKGROUND AND PURPOSE: Walker-Warburg syndrome, muscle-eye-brain disease, and Fukuyama congenital muscular dystrophy are $\alpha$-dystroglycan-related muscular disorders associated with brain malformations and eye abnormalities in which no structural inner ear abnormality has been described radiologically. We collected patients from 6 tertiary pediatric hospitals and reported the radiologic features and frequency of inner ear dysplasias.
\end{abstract}

MATERIALS AND METHODS: Patients previously diagnosed clinicoradiologically with Walker-Warburg syndrome, muscle-eye-brain disease, or Fukuyama congenital muscular dystrophy were included. We recorded the pathogenic variant, when available. Brain MR imaging and/or CT findings were reviewed in consensus, and inner ear anomalies were classified according to previous description in the literature. We then correlated the clinicoradiologic phenotype with the inner ear phenotype.

RESULTS: Thirteen patients fulfilled the criteria for the Walker-Warburg syndrome phenotype, 8 for muscle-eye-brain disease, and 3 for Fukuyama congenital muscular dystrophy. A dysplastic cochlea was demonstrated in 17/24. The most frequent finding was a pronounced cochlear hypoplasia type 4 with a very small anteriorly offset turn beyond the normal-appearing basal turn (12/13 patients with WalkerWarburg syndrome and 1/11 with muscle-eye-brain disease or Fukuyama congenital muscular dystophy). Two of 8 patients with muscleeye-brain disease, 1/3 with Fukuyama congenital muscular dystrophy, and 1/13 with Walker-Warburg syndrome showed a less severe cochlear hypoplasia type 4. The remaining patients without Walker-Warburg syndrome were healthy. The vestibule and lateral semicircular canals of all patients were normal. Cranial nerve VIII was present in all patients with diagnostic MR imaging.

CONCLUSIONS: Most patients with the severe $\alpha$-dystroglycanopathy Walker-Warburg syndrome phenotype have a highly characteristic cochlear hypoplasia type 4. Patients with the milder variants, muscle-eye-brain disease and Fukuyama congenital muscular dystrophy, more frequently have a normal cochlea or milder forms of hypoplasia.

ABBREVIATIONS: $\mathrm{CH}=$ cochlear hypoplasia; $\mathrm{CH} 4$ AOUT = cochlear hypoplasia type 4 with anterior offset of the upper turn; FCMD = Fukuyama congenital muscular dystrophy; $\mathrm{MEB}=$ muscle-eye-brain disease; $\mathrm{SNHL}=$ sensorineural hearing loss; WWS = Walker-Warburg syndrome

$\mathbf{T}$ he $\alpha$-dystroglycanopathies constitute a heterogeneous group of autosomal recessive disorders associated with muscular

\footnotetext{
Received June 6, 2020; accepted after revision August 16.

From the Department of Diagnostics and Pathology (G.T.), Neuroradiology Unit, Verona University Hospital, Verona, Italy; Division of Neuroradiology (C.R.), Department of Radiology, Boston Children's Hospital and Harvard Medical School, Boston, Massachusetts; Neuroradiology Unit (M.S.S.), Istituti di Ricovero e Cura a Carattere Scientifico, Istituto Giannina Gaslini, Genova, Italy; Department of Radiology and Division of Neuroradiology (C.A.A.), Children's Hospital of Philadelphia, Philadelphia, Pennsylvania; The Prenatal Diagnosis and Medical Genetics Program (D.C.), Department of Obstetrics and Gynecology, Mount Sinai Hospital University of Toronto, Toronto, Ontario, Canada; Department of Radiology (H.D.), Lucile Packard Children's Hospital, Stanford University School of Medicine, Stanford, California; Dental and Maxillofacial Surgery Department (L.S.), Great Ormond Street Hospital, London, UK; Dubowitz Neuromuscular Centre (F.M.), UCL Great Ormond Street Institute of Child Health and Great Ormond Street Hospital, London, UK; Division of Neuroradiology (S.I.B.), Department of Diagnostic Imaging, The Hospital for Sick Children, Toronto, Ontario, Canada; and Neuroradiology Unit (F.D.), Department of Radiology, Great Ormond Street Hospital for Children, National Health Service Trust, London, UK.
}

dystrophy due to a functional defect in the glycosylation of $\alpha$-dystroglycan, a cellular membrane adhesion complex that forms a bridge between the cytoskeleton and components of the extracellular matrix such as laminin. ${ }^{1}$ Most dystroglycanopathies involve a number of genes that code for glycosyltransferases, affecting the complex glycosylation of $\alpha$-dystroglycan and therefore limiting its ability to bind the extracellular-matrix ligands

\footnotetext{
This work was supported by the National Institute for Health Research, Great Ormond Street Hospital Biomedical Research Centre.

Please address correspondence to Felice D'Arco, MD, Neuroradiology Unit, Department of Radiology, Great Ormond St Hospital for Children NHS Trust, Gr. Ormond Street, WCIN3JH - London, United Kingdom; e-mail: felice.d'arco@gosh.nhs.uk

- Indicates open access to non-subscribers at www.ajnr.org

http://dx.doi.org/10.3174/ajnr.A6858
} 
(secondary dystroglycanopathies). ${ }^{2}$ Rare mutations in dystroglycan itself are also recognized (primary dystroglycanopathies).

Mutations in at least 18 genes have been found to be involved in the glycosylation of $\alpha$-dystroglycan, ${ }^{1,3}$ and the list is growing. However, a precise genotype-phenotype correlation is not possible, and the disease spectrum includes multiple phenotypes with overlapping clinical features and severity. This is because the effect of the mutation on the protein is more important than the gene per se because of the different degrees of $\alpha$-dystroglycan hypoglycosylation. ${ }^{3,4}$

Among these phenotypes, at the most severe end of the spectrum, Walker-Warburg syndrome (WWS), muscle-eye-brain disease (MEB), and Fukuyama congenital muscular dystrophy (FCMD) demonstrate brain malformations and ocular abnormalities, in addition to muscular dystrophy. Not surprisingly, the presence of malformations of cortical development of variable severity is associated with epilepsy and motor and language deficits. ${ }^{5}$ The characteristic malformations of cortical development in these patients, a cobblestone lissencephaly/polymicrogyria-like cortex, result from variable-sized gaps in the pial basement membrane and overmigration of neuronal cells, related to the role of $\alpha$-dystroglycan in the developing brain functioning as a link between radial glial cells and the pial basement membrane. ${ }^{3}$

Genetic mutations are an increasingly recognized cause of congenital hereditary sensorineural hearing loss (SNHL) and can be associated with various types of inner ear dysplasias. ${ }^{6,7}$ Syndromic associations have also been described, with multiple additional abnormalities involving other organ systems and, in some cases, recognition of a specific type of inner ear dysplasia that can guide genetic testing. ${ }^{8,9}$

There are only a few anecdotal reports of hearing loss in muscular dystrophy, including $\alpha$-dystroglycanopathies, but no structural abnormality has been described in a series of patients, to our knowledge. ${ }^{1,10-13}$

We hereby report the radiologic characteristics, frequency, and correlation with the clinicoradiologic phenotype of inner ear dysplasias encountered in a population of patients with $\alpha$-dystroglycanopathy collected from 6 tertiary pediatric hospitals.

\section{MATERIALS AND METHODS}

Cases were identified using the electronic patient record system of each institution, searching for WWS, MEB, and FCMD diagnoses and adding relevant keyword searches (eg, "a-dystroglycanopathy," "congenital muscular dystrophy," "cobblestone cortex," and "cerebellar cysts"). Appropriate governance permissions from each site were obtained.

Only patients previously diagnosed clinicoradiologically as having WWS, MEB, or FCMD were included. According to previous literature, ${ }^{3,4,10,11}$ a WWS phenotype was defined with observation of very early neurologic symptom onset (prenatally or at birth) and extreme brain abnormalities: complete agyria or severe lissencephaly/cobblestone, marked hydrocephalus, severe cerebellar hypoplasia/dysplasia, and complete or partial absence of the corpus callosum. In addition, a severely hypoplastic and "kinked" brain stem was determined as a characteristic feature of WWS and considered an inclusion criterion in this category. ${ }^{10}$ Eye abnormalities include congenital cataracts, microphthalmia, and buphthalmos.
MEB and FCMD phenotypes were defined when brain abnormalities were less severe than those seen with WWS: pachygyria/ polymicrogyria-like/cobblestone cortex with preferential frontoparietal involvement, cerebellar hypo/dysplasia, and less severe brain stem anomalies, including a posterior "bowing" (a posterior concavity less severe than that observed in kinked brain stem). ${ }^{3,10}$ Despite a recognized radiologic overlap between MEB and FCMD, ${ }^{4}$ clinically, cardiac and respiratory problems with less severe epilepsy were more typical of FCMD, while more severe ocular abnormalities and the absence of cardiac/ respiratory features were more in keeping with MEB., ${ }^{3,10,11}$

When pathogenic genetic mutations were available, they were recorded; however, given the weak genotype/phenotype correlation in these disorders, we correlated the clinicoradiologic phenotype with the inner ear phenotype.

The authors retrospectively reviewed, by consensus, the brain MR imaging and/or CT findings (anonymized). MRIs were acquired on different scanners (both $1.5 \mathrm{~T}$ and $3 \mathrm{~T}$ ) and with different protocols. An axial T2 brain sequence (section thickness, 2$3 \mathrm{~mm}$ ) or a high-resolution 3D steady-state sequence of the internal auditory meatus was used to assess the inner ears. The axial T2 was considered diagnostic when cochleae were visualized in at least 2 slices (basal turns in the most caudal one and middle/apical turns in the cranial one).

Available CT scans were acquired with a standard brain protocol and subsequent bone algorithm reconstructions (1- $\mathrm{mm} \mathrm{sec-}$ tion thickness).

Inner ear anomalies were reviewed and classified according to previous literature. ${ }^{6,9}$ More specifically, cochlear hypoplasia $(\mathrm{CH})$ was defined as a cochlea with a small external size and a less than normal number of $2 \frac{1}{2}-2 \frac{3}{4}$ turns. The definition of each $\mathrm{CH}$ subtype was previously described in histologic and radiologic studies: ${ }^{6,12}$ 1) CH-1: tiny budlike cochlea without an internal structure; 2) $\mathrm{CH}-2$ : a small cochlea with a modiolus or interscalar septa, which are present but defective; 3) $\mathrm{CH}-3$ : the internal and external architecture (modiolus, interscalar septa) is similar to that of a normal cochlea, but the overall size is smaller with fewer or shorter turns; and 4) CH-4: a small cochlea with a normal basal turn but hypoplastic middle and apical turns.

In addition, an anterior offset of the cochlear middle turn was recorded when there was "anteromedial angulation and displacement of the middle and apical turns of the cochlea away from the basal turn," similar to the cochlea malformation described in branchio-oto-renal syndrome. ${ }^{13}$

Patients who did not fulfill the clinicoradiologic criteria for WWS, MEB, or FCMD or with images suboptimal for cochlear assessment were excluded.

\section{RESULTS}

After initial research, we excluded 3 patients: 2 with MEB with suboptimal images and an aborted 20-week fetus with severe cortical malformation and kinking of the brain stem but without clinical criteria or genetic mutations available at the time of the report and no postnatal MR imaging performed.

Twenty-four patients with congenital muscular dystrophy due to secondary dystroglycanopathies were found. Fourteen (14/24) were males (age range, 1 day to 21 years). Thirteen of 24 showed a 
Demographic, genetic and radiological characteristics of the patients

\begin{tabular}{|c|c|c|c|c|c|c|}
\hline & Sex & $\begin{array}{l}\text { Age at } \\
\text { Imaging }\end{array}$ & $\begin{array}{l}\text { Clinicoradiologic } \\
\text { Phenotype }\end{array}$ & $\begin{array}{l}\text { Genetic } \\
\text { Mutation }\end{array}$ & $\begin{array}{l}\text { Cochlear } \\
\text { Phenotype }\end{array}$ & $\begin{array}{l}\text { Imaging Where Cochlea } \\
\text { Was Assessed }\end{array}$ \\
\hline Patient 1 & $M$ & $5 \mathrm{mo}$ & WWS & POMT7 & $\mathrm{CH} 4 \mathrm{AOUT}$ & MR imaging brain, $\mathrm{CT}$ brain \\
\hline Patient 2 & M & $3 \mathrm{mo}$ & WWS & POMT7 & $\mathrm{CH} 4 \mathrm{AOUT}$ & MR imaging brain, $\mathrm{CT}$ brain \\
\hline Patient 3 & $\mathrm{~F}$ & 15 days & WWS & POMT2 & $\mathrm{CH} 4 \mathrm{AOUT}$ & MR imaging brain, $\mathrm{CT}$ brain \\
\hline Patient 4 & $\mathrm{~F}$ & 1 day & WWS & POMTI & $\mathrm{CH} 4 \mathrm{AOUT}$ & MR imaging brain (axial T2) \\
\hline Patient 5 & M & 1 day & WWS & FKRP & $\mathrm{CH} 4 \mathrm{AOUT}$ & MR imaging brain, $\mathrm{CT}$ brain \\
\hline Patient 6 & M & $4 \mathrm{yr}$ & WWS & Not available & $\begin{array}{l}\mathrm{CH} 4 \text { (less severe } \\
\text { phenotype) }\end{array}$ & MR imaging brain (axial T2) \\
\hline Patient 7 & $\mathrm{~F}$ & $2 \mathrm{mo}$ & WWS & Not available & CH4 AOUT & MR imaging brain (axial T2) \\
\hline Patient 8 & M & 9 days & WWS & Not available & CH4 AOUT & MR imaging brain (axial T2) \\
\hline Patient 9 & $\mathrm{~F}$ & $4 \mathrm{mo}$ & WWS & $B 3 G N T 7$ & CH4 AOUT & MR imaging brain, $\mathrm{CT}$ brain \\
\hline Patient 10 & $\mathrm{~F}$ & $18 \mathrm{mo}$ & WWS & FKTN & $\mathrm{CH} 4 \mathrm{AOUT}$ & MR imaging brain, CT brain \\
\hline Patient 11 & $\mathrm{~F}$ & $7 \mathrm{mo}$ & WWS & POMTI & $\mathrm{CH} 4 \mathrm{AOUT}$ & $\begin{array}{l}\text { MR imaging brain, CT brain, } \\
\text { 3D T2 IAMs }\end{array}$ \\
\hline Patient 12 & M & $3 \mathrm{mo}$ & WWS & Not available & $\mathrm{CH} 4 \mathrm{AOUT}$ & MR imaging brain (axial T2) \\
\hline Patient 13 & $\mathrm{~F}$ & $2 \mathrm{mo}$ & WWS & Not available & CH4 AOUT & MR imaging brain (axial T2) \\
\hline Patient 14 & M & $2.5 \mathrm{yr}$ & MEB & POMGnT1 & $\begin{array}{l}\mathrm{CH} 4 \text { (less severe } \\
\text { phenotype) }\end{array}$ & MR imaging brain (axial T2) \\
\hline Patient 15 & $\mathrm{~F}$ & $7 \mathrm{yr}$ & MEB & POMGNTI & Normal & MR imaging brain, $\mathrm{CT}$ brain \\
\hline Patient 16 & M & $3 \mathrm{mo}$ & MEB & POMGnTl & Normal & MR imaging brain, $\mathrm{CT}$ brain \\
\hline Patient 17 & M & 2 days & MEB & POMGnT7 & Normal & MR imaging brain (axial T2) \\
\hline Patient 18 & M & $21 \mathrm{yr}$ & MEB & POMGnT7 & Normal & MR imaging brain (axial T2) \\
\hline Patient 19 & M & $1 \mathrm{yr}$ & MEB & POMT2 & CH4 AOUT & $\begin{array}{l}\text { MR imaging brain (axial T2), } \\
\text { 3D-T2 IAMs }\end{array}$ \\
\hline Patient 20 & M & $11 \mathrm{mo}$ & MEB & POMGNT2 & $\begin{array}{l}\mathrm{CH} 4 \text { (less severe } \\
\text { phenotype) }\end{array}$ & MR imaging brain (axial T2) \\
\hline Patient 21 & M & $9 \mathrm{mo}$ & MEB & Not available & Normal & MR imaging brain (axial T2) \\
\hline Patient 22 & M & $6 \mathrm{mo}$ & Fukuyama & FKRP & Normal & MR imaging brain (axial T2) \\
\hline Patient 23 & $\mathrm{~F}$ & 2 days & Fukuyama & FKRP & $\begin{array}{l}\mathrm{CH} 4 \text { (less severe } \\
\text { phenotype) }\end{array}$ & MR imaging brain, $\mathrm{CT}$ brain \\
\hline Patient 24 & $\mathrm{~F}$ & $14 \mathrm{mo}$ & Fukuyama & Not available & Normal & MR imaging brain (axial T2) \\
\hline
\end{tabular}

Note:-IAMs indicates internal auditory meatus.

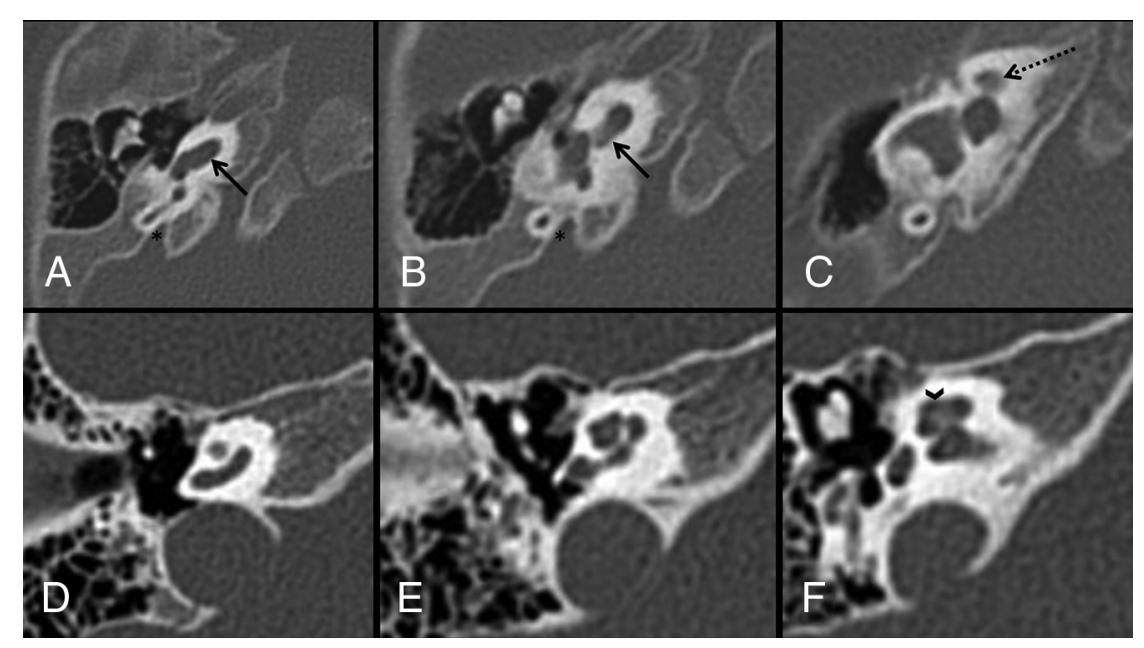

FIG 1. Axial CT with thin bone reformats in patient 1 . The WWS phenotype and POMT7 variant $(A, B$, and $C$ ) show a characteristic CH4 AOUT with a normal basal turn (arrows in $A$ and $B$ ) and a very hypoplastic and anteromedially displaced upper part of the cochlea (dashed arrow in $C$ ). The abnormality was symmetric on both sides. Note the normal appearance of the semicircular canals and vestibule. The vestibular aqueducts (asterisk in $A$ and $B$ ), despite looking slightly enlarged on subjective analysis, were within normal limits when measured. A normal cochlea for comparison $(D, E$, and $F$ ) shows well-developed middle and apical turns (arrowhead in $F$ ).
Dysplastic cochlear morphology was found in 17/24; in all cases, the abnormality was bilateral and symmetric. Cochlear morphology appeared normal in 7/24 (Table).

The most frequent finding was characteristic cochlear hypoplasia with a normal basal turn and extremely hypoplastic upper turns that appeared offset anteriorly with respect to the basal turn. Given the normal basal turn, this was classified as a $\mathrm{CH}$ type 4 (Figs 1 and 2).

This morphology was found in $13 / 24$ patients. Most interestingly, the pronounced $\mathrm{CH} 4$ with an anterior offset of the upper turn (CH4 AOUT) was present in $12 / 13$ of patients with WWS but only $1 / 11$ of the remaining phenotypes, a patient with MEB. The remaining patient with WWS also had a small cochlea with a normal basal turn $(\mathrm{CH} 4)^{6,12}$ but with better devel-
WWS phenotype; 8/24, an MEB phenotype; and 3/24, an FCMD phenotype. Genetic confirmation was available in 17/24 cases: 5 POMGNT1, 4 POMT1, 2 POMT2, 3 FKRP, 1 FKTN, 1 B3GNT1, and 1 POMGNT2. oped upper turns, similar to the other less severe $\mathrm{CH} 4$ found in some of the patients with MEB and FCMD (Fig 3). Among the MEB phenotypes, 5/8 patients had normal cochleae, $1 / 8$ had $\mathrm{CH} 4$ AOUT, and 2/8 showed a less severe form of $\mathrm{CH} 4$. Patients with 
FCMD had normal cochleae in 2/3 cases, while 1 subject had a less severe form of $\mathrm{CH} 4$. In all patients, we found that the vestibules and semicircular canals were normal (Fig 2). The vestibulocochlear nerves were bilaterally present in all cases (on axial T2 images).

No audiometric correlation was available because hearing function is not routinely evaluated in these patients.

\section{DISCUSSION}

Mutations in 18 currently known genes can cause defective glycosylation of $\alpha$-dystroglycan and, consequently, a subset of congenital muscular dystrophies called secondary dystroglycanopathies. These diseases vary in severity from mild adult-onset limb-girdle muscular dystrophy to more severe phenotypes with early-onset and eye and brain involvement. ${ }^{3}$ Brain malformations have been extensively described in patients at the severe end of the clinical spectrum and were used as one of the diagnostic criteria, even before the genetic profile was recognized. ${ }^{14}$

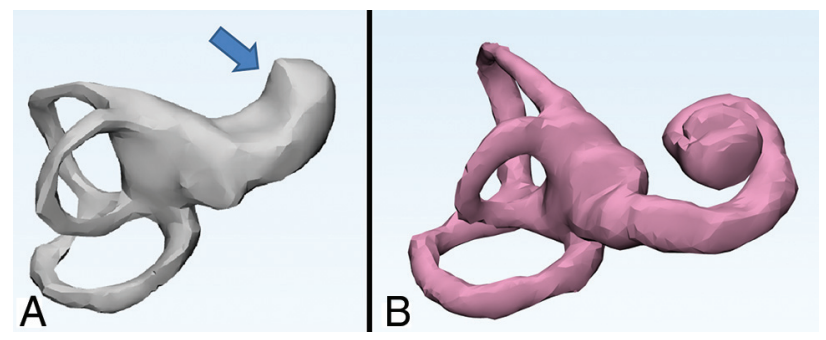

FIG 2. 3D volume-rendering of the $\mathrm{CH} 4$ AOUT in patient 2 with a WWS phenotype and $P O M T$ variant $(A)$ in comparison with a healthy control ( $B$ ). Note the marked cochlear hypoplasia in $A$ (arrow) in comparison with normal $2 \frac{1}{2}$ cochlear turns in $B$. The vestibule and lateral semicircular canals are normal in both patients.

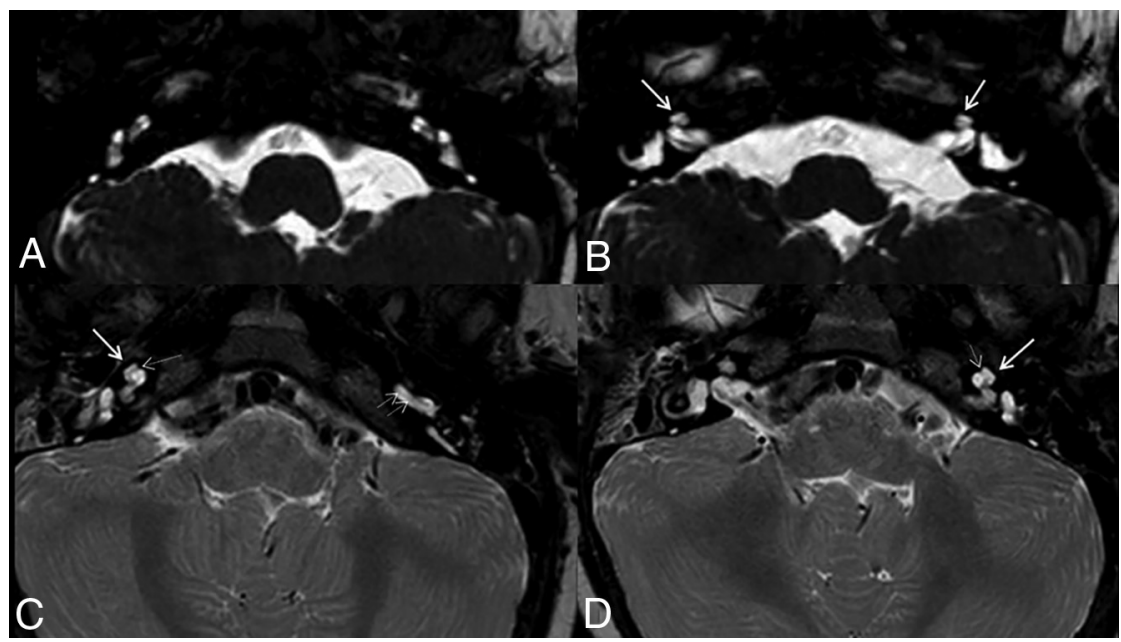

FIG 3. A variable cochlear appearance in MEB phenotypes. High-resolution steady-state (CISS) images in patient 19 ( $A$ and $B$ ) show a pronounced hypoplastic cochlea, similar to the cases of WWS with a small "budlike" protuberance that is anteriorly offset (arrows in B). Axial T2 (section thickness, $3 \mathrm{~mm}$ ) in patient 20 shows a hypoplastic cochlea with a more developed middle turn (arrows in $C$ and $D$ ) and visualization of medial interscalar septum (thin dotted arrow). Note the thin linear hypointensity within the fluid signal of the basal turn, in keeping with a preserved lamina spiralis well-seen in both patients (double arrow in C).
An important concept, useful in the interpretation of our data, is that in secondary dystroglycanopathies, a precise genotype/phenotype correlation is not possible because the mutations in the same gene can cause a variety of different phenotypes and these diseases should be considered as a clinicoradiologic spectrum. This is mainly due to the effect of individual mutations on the glycosylation of $\alpha$-dystroglycan, with WWS representing the extremely severe variant. ${ }^{3,4}$ A relatively milder form of congenital muscular dystrophy with structural brain involvement is represented by MEB/FCMD, usually associated with founder mutations in POMGNT1 and FKTN, but less frequently associated with most of the other genes. ${ }^{4,11}$

Thus, we decided to correlate the clinicoradiologic phenotype (rather than genotype) with inner ear appearances, and in doing so, we found that $100 \%$ of patients with WWS showed striking cochlear abnormalities (12/13 had a characteristic CH4 AOUT), while only 4/11 with MEB/FCMD had cochlear abnormalities and only 1 had CH4 AOUT. Therefore, the cochlea seems to predict the brain to some extent.

Very few reports of children with congenital muscular dystrophies and SNHL have been previously published. ${ }^{15}$ Carss et $\mathrm{al}^{1}$ published a case series of 8 patients with $\alpha$-dystroglycanopathy due to $G M P P B$ variants: among them, a patient with an MED/FCMD phenotype and "pontine and cerebellar hypoplasia" had SNHL. Later on, a patient with a FKRP variant was reported to have unusually severe eye abnormalities and SNHL. ${ }^{16}$ Bilateral SNHL has been recently reported in 12 subjects with the B3GALNT2 variant, severe brain malformations (mostly cobblestone/polymicrogyria spectrum and pontocerebellar hypoplasia/dysplasia), and epilepsy, but no morphologic description of the inner ear anomalies was available. ${ }^{17}$ Furthermore, microstructural changes in the cochlea have been described in a laminin-deficient $d y$ mouse model of congenital muscular dystrophy, implying that laminin is critical in the cochlear function and development. ${ }^{18}$ The role of the laminin is further supported by the presence of antibodies against laminin in various forms of hearing loss. ${ }^{19}$ Finally, SNHL has been noted in a patient with limb-girdle muscular dystrophy ${ }^{20}$ and in 2 siblings with arthrogryposis multiplex congenita and cobblestone lissencephaly. ${ }^{21}$

Hence, hearing loss may be a largely under-recognized feature of the severe $\alpha$-dystroglycanopathies with central nervous system involvement, noting that the genetic link is not as yet well-established.

It is interesting that all the inner ear dysplasias in this series exclusively involved the cochlear portion of the labyrinth. No other abnormality was found in the inner ear (normal vestibule and semicircular canals). 
A number of gene families are of critical importance in the embryogenesis of the otic capsule-derived structures (eg, FOX, DIX, FGF, PAX, and SOX), and correlations have been found between some pathogenic genes and characteristic inner ear malformations. ${ }^{9,22,23}$ Moreover, some of these genes are significantly involved in the embryogenesis of other systems, producing quite notable syndromic associations. ${ }^{8}$

According to the "compartment boundary model" of inner ear development, particular genes are involved in the development of the ventral portion of the otic capsule (ie, cochlear morphogenesis), while others are involved in the development of the vestibule or semicircular canals.

Although much is still unknown about the "symphony of inner ear development control genes" (as described by Chatterjee et $\mathrm{al}^{24}$ ), we know that for instance, Shh maintains Pax2 in the medial and ventral wall of the forming otic vesicle determining the cochlear fate, while wht and Dlx5/Dlx6 are involved in the development of the vestibule and semicircular canals.

In fact, Pax2 knockout mice demonstrate an absent cochlea, while other genes can account for the loss of $\geq 1$ semicircular canal. $^{22}$ It is then possible that in dystroglycanopathies, the functions of $\geq 1$ gene determining exclusively the cochlear fate, rather than the development of the otic capsule as a whole, are impaired.

There is other evidence that may be relevant in explaining the specific cochlear phenotype in our patients: 1) The sensory precursor cells are under the control of many cyclin-dependent kinase inhibitors, including p27, which is more active when the cochlea starts to develop the middle and apical turns and after the development of the basal turn (exactly when the cochlear development is arrested in case of $\mathrm{CH} 4) ;{ }^{25}$ and 2) the GG domain (a widely distributed protein motif) is present in POMGnT1 (mutated in MEB) but also in cases of nonsyndromic hearing loss. ${ }^{1,17,26}$

Finally, insights can come from the embryology; according to Sennaroglu, ${ }^{7} \mathrm{CH}-4$ is likely a genetically determined hypoplasia in which the arrest in the membranous labyrinth development happens between the 10th and 20th week before the middle and apical turns reach normal size but the basal turn has already fully developed. Therefore, it is possible that the $\mathrm{CH} 4$ morphology in patients with WWS is due to a genetically determined arrested development between the 10th and 20th week, associated with the malfunction of genes that are specifically involved in the development of the cochlea. Cochlear hypoplasia type 4 can also be found in other genetically determined syndromes ${ }^{8}$ and does not constitute a pathognomonic feature of dystroglycanopathies. However, in the appropriate clinicoradiologic context, such a marked hypoplastic phenotype seems to be fairly specific for the WWS phenotype.

The main limitation of this study is its retrospective nature and the fact that all except $2 \mathrm{MR}$ imaging studies consisted of routine brain sequences rather than detailed sequences for the inner ear. Nevertheless, on CT and 2- to 3-mm axial T2-weighted images of the brain, the cochlea can be adequately assessed by experienced pediatric neuroradiologists in consensus. If possible, adding a high-resolution 3D steady-state sequence to the MR imaging protocol would be ideal to depict the abnormality. Also, when available, we found that thin bone reformats of a CT of the head obtained for hydrocephalus are enough to characterize the cochlear abnormalities in those patients.

Another potential bias lies in the clinical diagnosis of these syndromes, which, in itself, is often challenging and commonly presents with overlapping features. To avoid misinterpretation of the correct diagnosis, a clinical and radiologic analysis was required to confirm that each subject fulfilled the criteria for each syndrome.

\section{CONCLUSIONS}

This is the first radiologic description of inner ear dysplasias in a relatively large series of patients with $\alpha$-dystroglycanopathies characterized by distinct pronounced hypoplasia of the middle cochlear turns, which appears anteriorly offset from the basal turn, with an absent/deficient apical turn in most WWS phenotypes and with less frequent and less marked dysplasia (but again limited to the cochlea) in the MEB and FCMD phenotypes. This evidence lays the foundation for further studies investigating the genetic link between ear development and $\alpha$-dystroglycanopathies, which may help in understanding the factors specifically responsible for cochlear development.

\section{ACKNOWLEDGMENTS}

We would like to thank Mr Juling Ong, consultant craniofacial and pediatric plastic surgeon at Great Ormond Street Hospital, for supervising the 3D reformatting and 3D printing of the cochlear abnormalities.

Disclosures: Mariasavina Severino-UNRELATED: Employment: Neuroradiology Consultant at Istituti di Ricovero e Cura a Carattere Scientifico, Istituto Giannina Gaslini. Francesco Muntoni-UNRELATED: Consultancy: Sarepta Therapeutics, Biogen, AveXis, Pfizer, Roche, Comments: SABs; Grants/Grants Pending: Sarepta Therapeutics, Biogen, Comments: investigator-initiated studies; Payment for Lectures Including Service on Speakers Bureaus: Sarepta Therapeutics, Biogen, AveXis, Roche, Comments: meetings and symposia. Susan I. Blaser-UNRELATED: Royalties: Elsevier.

\section{REFERENCES}

1. Carss KJ, Stevens E, Foley AR, et al; UK10K Consortium. Mutations in GDP-mannose pyrophosphorylase B cause congenital and limbgirdle muscular dystrophies associated with hypoglycosylation of $\alpha$-dystroglycan. Am J Hum Genet 2013;93:29-41 CrossRef Medline

2. Brancaccio A. A molecular overview of the primary dystroglycanopathies. J Cell Mol Med 2019;23:3058-62 CrossRef Medline

3. Brun BN, Mockler SR, Laubscher KM, et al. Comparison of brain MRI findings with language and motor function in the dystroglycanopathies. Neurology 2017;88:623-29 CrossRef Medline

4. Godfrey C, Clement E, Mein R, et al. Refining genotype phenotype correlations in muscular dystrophies with defective glycosylation of dystroglycan. Brain 2007;130:2725-35 CrossRef Medline

5. Martin PT. The dystroglycanopathies: the new disorders of $\mathrm{O}$ linked glycosylation. Semin Pediatr Neurol 2005;12:152-58 CrossRef Medline

6. Talenti G, Manara R, Brotto D, et al. High-resolution $3 \mathrm{~T}$ magnetic resonance findings in cochlear hypoplasias and incomplete partition anomalies: a pictorial essay. Br J Radiol 2018;91:20180120 CrossRef Medline 
7. Sennaroglu L. Histopathology of inner ear malformations: do we have enough evidence to explain pathophysiology?. Cochlear Implants Int 2016;17:3-20 CrossRef Medline

8. D'Arco F, Youssef A, Ioannidou E, et al. Temporal bone and intracranial abnormalities in syndromic causes of hearing loss: an updated guide. Eur J Radiol 2020;123:108803 CrossRef Medline

9. D'Arco F, Sanverdi E, O'Brien WT, et al. The link between inner ear malformations and the rest of the body: what we know so far about genetic, imaging and histology. Neuroradiology 2020;62:539-44 CrossRef Medline

10. Barkovich AJ. Neuroimaging manifestations and classification of congenital muscular dystrophies. AJNR Am J Neuroradiol 1998;198: 1389-96 Medline

11. Kang PB, Morrison L, Iannaccone ST, et al; Guideline Development Subcommittee of the American Academy of Neurology and the Practice Issues Review Panel of the American Association of Neuromuscular \& Electrodiagnostic Medicine. Evidence-based guideline summary: evaluation, diagnosis, and management of congenital muscular dystrophy: Report of the Guideline Development Subcommittee of the American Academy of Neurology and the Practice Issues Review Panel of the American Association of Neuromuscular \& Electrodiagnostic Medicine. Neurology 2015;85:1432-78 CrossRef Medline

12. Sennaroğlu L, Bajin MD, Pamuk E, et al. Cochlear hypoplasia type four with anteriorly displaced facial nerve canal. Otol Neurotol 2016;37:e407-09 CrossRef Medline

13. Hsu A, Desai N, Paldino MJ. The unwound cochlea: a specific imaging marker of branchio-oto-renal syndrome. AJNR Am J Neuroradiol 2018;39:2345-49 CrossRef Medline

14. Dobyns WB, Pagon RA, Armstrong D, et al. Diagnostic criteria for Walker-Warburg syndrome. Am J Med Genet 1989;32:195-210 CrossRef Medline

15. Bigoni S, Mauro A, Ferlini A, et al. Cochlear malformation and sensorineural hearing loss in the Silver-Russell Syndrome. Minerva Pediatr 2018;70:380-81 CrossRef
16. Kava M, Chitayat D, Blaser S, et al. Eye and brain abnormalities in congenital muscular dystrophies caused by fukutin-related protein gene (FKRP) mutations. Pediatr Neurol 2013;49:374-78 CrossRef Medline

17. Al Dhaibani MA, El-Hattab AW, Ismayl O, et al. B3GALNT2-related dystroglycanopathy: expansion of the phenotype with novel mutation associated with muscle-eye-brain disease, Walker-Warburg Syndrome, epileptic encephalopathy-West syndrome, and sensorineural hearing loss. Neuropediatrics 2018;49:289-95 CrossRef Medline

18. Pillers DA, Kempton JB, Duncan NM, et al. Hearing loss in the laminin-deficient dy mouse model of congenital muscular dystrophy. Mol Genet Metab 2002;76:217-24 CrossRef Medline

19. Klein R, Timpl R, Zanetti FR, et al. Ann Otol Rhinol Laryngol 1989;98:537-42 CrossRef Medline

20. Oexle K, Herrmann R, Dodé C, et al. Neurosensory hearing loss in secondary adhalinopathy. Neuropediatrics 1996;27:32-36 CrossRef Medline

21. Seidahmed MZ, Sunada Y, Ozo CO, et al. Lethal congenital muscular dystrophy in two sibs with arthrogryposis multiplex: new entity or variant of cobblestone lissencephaly syndrome? Neuropediatrics 1996;27:305-10 CrossRef Medline

22. Som PM, Curtin HD, Liu K, et al. Current embryology of the temporal bone, Part I: the inner ear. Neurographics 2016;6:250-65 CrossRef

23. Siddiqui A, D'Amico A, Colafati GS, et al. Hypothalamic malformations in patients with $\mathrm{X}$-linked deafness and incomplete partition type 3. Neuroradiology 2019;61:949-52 CrossRef Medline

24. Chatterjee S, Kraus P, Lufkin T. A symphony of inner ear developmental control genes. BMC Genet 2010;11:68 CrossRef Medline

25. Kelly MC, Chen P. Development of form and function in the mammalian cochlea. Curr Opin Neurobiol 2009;19:395-401 CrossRef Medline

26. Guo J, Cheng $\mathrm{H}$, Zhao $\mathrm{S}$, et al. GG: a domain involved in phage LTF apparatus and implicated in human MEB and non-syndromic hearing loss diseases. FEBS Lett 2006;580:581-84 CrossRef Medline 